\title{
Hidroquímica dos aquíferos Tubarão e Cristalino na região de Indaiatuba-Rafard, Estado de São Paulo
}

\author{
Sibele EZAKI ${ }^{1}$, Geraldo, H. ODA ${ }^{1}$, Mara A. IRITANI ${ }^{1}$, Carla VEIGA² \& Márcia R. STRADIOTO³ \\ 1. Instituto Geológico, Secretaria do Meio Ambiente do Estado de São Paulo. Av. Miguel Stéfano 3900, CEP 04301-903, São Paulo, SP, Brasil. \\ E-mail: sibezaki@igeologico.sp.gov.br, mara.iritani@igeologico.sp.gov.br, ghoda1947@gmail.com. \\ 2. Agência Nacional de Águas - ANA. Setor Policial, área 5, Quadra 3, Blocos "B", "L", "M", e "T", CEP 70610-200, Brasília, DF, Brasil. E-mail: \\ carla.veiga@gmail.com. \\ 3. Laboratório de Estudos de Bacias, Instituto de Geociências e Ciências Exatas, Universidade Estadual Paulista, Av. 24-A, 515, CEP 13506- \\ 900, Rio Claro, SP, Brasil. E-mail: marciastradioto@uol.com.br.
}

Recebido em 04/2013. Aceito para publicação em 02/2014.

Versão online publicada em 15/05/2014 (www.pesquisasemgeociencias.ufrgs.br)

\begin{abstract}
Resumo - Este trabalho apresenta uma caracterização hidroquímica e da qualidade da água subterrânea dos aquíferos Tubarão (sedimentar, granular) e Cristalino (fissural) na porção sul da Bacia Hidrográfica dos rios Piracicaba, Capivari e Jundiaí (UGRHI 05) que abrange os municípios de Indaiatuba, Salto, Monte Mor, Elias Fausto, Capivari e Rafard, Estado de São Paulo. O Aquífero Cristalino apresenta águas predominantemente bicarbonatadas cálcicas e sódicas, com pH médio de 7,35, enquanto as águas do Aquífero Tubarão são bicarbonatadas sódicas, com pH médio de 8,15, e ocorrência de águas sulfatadas sódicas. De modo geral, a salinidade e concentração de sódio destas águas tende a aumentar no sentido do fluxo subterrâneo das áreas de recarga para as de descarga nos principais rios da região. A correlação de dados isotópicos de $\delta \mathrm{D}$ e $\delta^{18} 0$ evidenciou a influência de águas meteóricas na composição de ambos os aquíferos, mas também indicou que algumas porções do Aquífero Tubarão estão confinadas com a presença de águas de recarga mais antigas e associadas a um período em que o clima era frio. Nas análises químicas de poços amostrados e de laudos de relatórios de poços, foram averiguados alguns parâmetros que se apresentam acima do padrão de potabilidade como fluoreto, sólidos totais dissolvidos, ferro total, manganês e nitrato. A ocorrência de elevados teores de F- e STD está associada a anomalias naturais da região; $\mathrm{Fe}(\mathrm{t})$ e $\mathrm{Mn}^{2+}$ podem estar relacionados às características das formações geológicas embora sejam necessários estudos complementares para averiguar a influência de fontes de contaminação ou de problemas construtivos de poços. Casos de contaminação por $\mathrm{NO}_{3}$ - são ainda pontuais, e indicam influência de cargas potenciais associadas à ocupação urbana e que merecem um monitoramento. Palavras-chave: Hidroquímica, Aquífero Tubarão, Aquífero Cristalino, águas subterrâneas, qualidade
\end{abstract}

\begin{abstract}
Hydrochemistry of Tubarão and Crystalline Aquifers in Indaiatuba-Rafard Region, São Paulo State. This paper presents a hydrochemical and groundwater quality characterization of the aquifers Tubarão (sedimentary, granular) and Crystalline (fissural) in the southern portion of the Basin of Piracicaba, Capivari and Jundiaí Rivers (UGRHI 05) which involves the municipalities of Indaiatuba, Salto, Monte Mor, Elias Fausto, Capivari and Rafard, São Paulo State. The Crystalline Aquifer waters are predominantly calcium and sodium bicarbonate, with $\mathrm{pH}$ average of 7.35, while the waters of Tubarão Aquifer are sodium bicarbonate, with $\mathrm{pH}$ average of 8.15, and occurrence of sodium sulfate waters. The sodium concentration and salinity of these groundwaters tend to rise usually in the direction of groundwater flow, from recharge areas to discharge areas in the main rivers. The correlation of isotopic data $\delta \mathrm{D}$ and $\delta^{18} \mathrm{O}$ demonstrated an influence of rainwater on the composition of both aquifers, but also indicated that certain portions of the Tubarão Aquifer are confined with the presence of older recharged waters associated with a cold weather period of time. Chemical analyzes of sampled well waters and of well reports, indicate some parameters that exceeded potability standard values: fluoride, total dissolved solids, total iron, manganese and nitrate. The occurrence of high levels of $\mathrm{F}^{-}$and TDS is associated with natural anomalies of the region; $\mathrm{Fe}(\mathrm{t})$ and $\mathrm{Mn}^{2+}$ may be related to the characteristics of the geological formations, although additional studies are necessary to investigate the influence of sources of contamination or well construction problems. Contamination cases by $\mathrm{NO}_{3}{ }^{-}$are still punctual and indicate a potential influence of sewage loads associated with the urban occupation and must be monitored.
\end{abstract}

Keywords: Hydrochemistry, Tubarão Aquifer, Crystalline Aquifer, ground water, quality

\section{Introdução}

A região que abrange os municípios entre Indaiatuba e Rafard (SP) apresenta crescente demanda por água subterrânea tanto para abastecimento público como para usos privados, decorrente do crescimento populacional, desenvolvimento econômico e expansão urbana. A procura por este recurso intensificou-se nas duas últimas décadas, apesar da baixa disponibilidade hídrica relacionada às características intrínsecas dos 
principais aquíferos explotados - Tubarão (sedimentar) e Cristalino (fissural) com vazões medianas de 7,3 $\mathrm{m}^{3} / \mathrm{h}$ e $7,0 \mathrm{~m}^{3} / \mathrm{h}$ (Pereira, 1997), respectivamente. Esta área situa-se a sul da região metropolitana de Campinas (SP) e apresenta problemas similares relacionados à degradação dos mananciais superficiais e consequente elevação do custo de tratamento dessas águas, assim como sinais de escassez. Nesse sentido, os mananciais subterrâneos se tornam importantes fontes alternativas para o abastecimento.
No Estado de São Paulo, aproximadamente 80\% dos municípios são total ou parcialmente abastecidos por água subterrânea. Na área estudada (Fig. 1) os municípios de Rafard e Elias Fausto dependem totalmente das águas subterrâneas para abastecimento público, enquanto os demais dependem parcialmente: Capivari $(63,72 \%)$, Monte Mor (45,95 \%) e Indaiatuba $(0,59$ \%). Somente Salto utiliza $100 \%$ de recursos hídricos superficiais (Sistema Nacional de Informações sobre Saneamento, 2008).

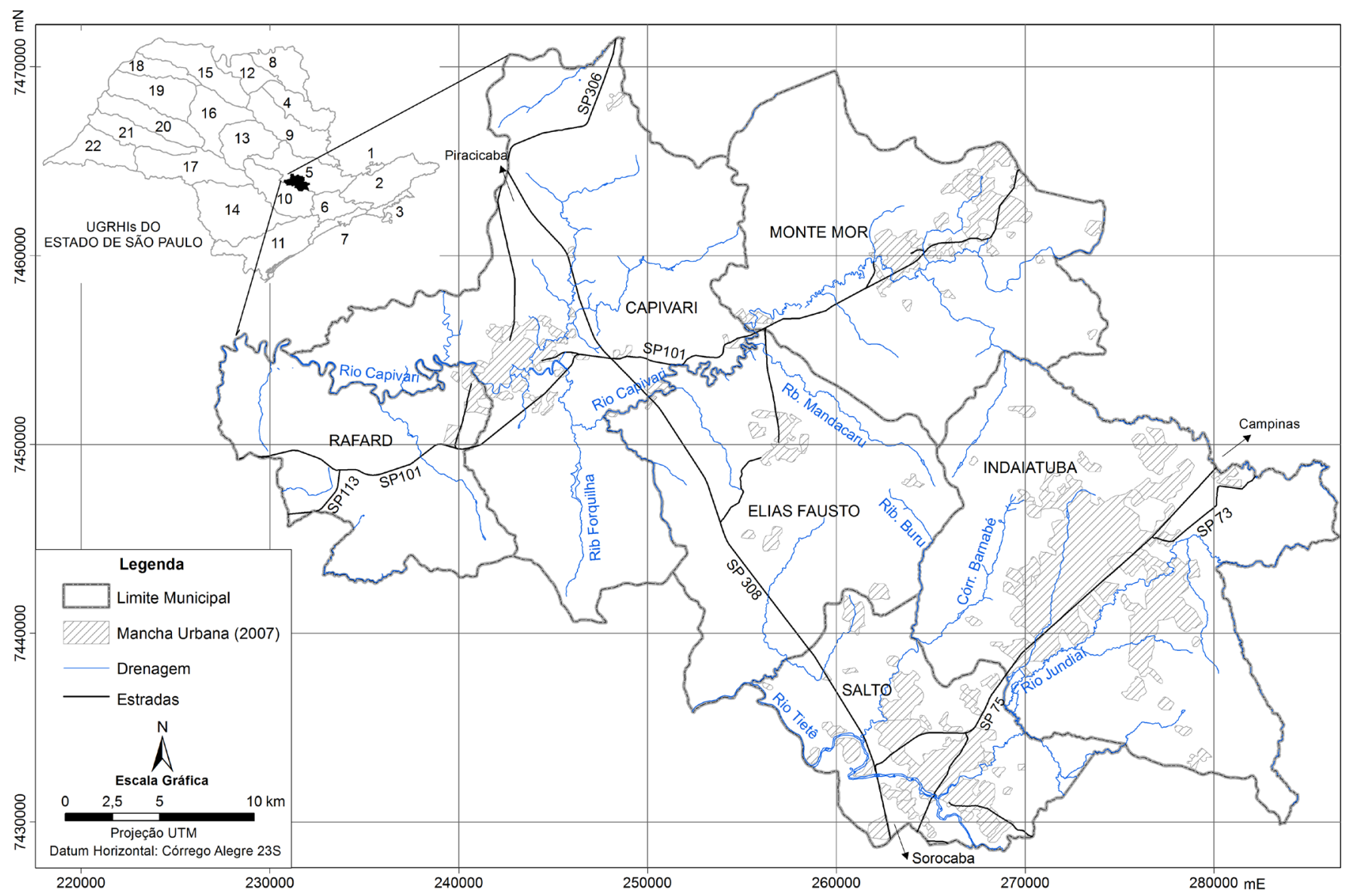

Figura 1. Localização da área de estudo.

Considerando o intenso processo de urbanização e de industrialização, é importante que haja avaliação das características naturais das águas subterrâneas, bem como da influência de potenciais fontes de contaminação (naturais ou de origem antrópica) sobre a sua qualidade, visando garantir o melhor aproveitamento e estabelecer medidas de proteção quando houver perigo.

Este trabalho tem como proposta a caracterização hidroquímica e isotópica dos aquíferos Tubarão e Cristalino, além da avaliação da qualidade das águas subterrâneas nos municípios indicados, levando-se em consideração a ocorrência de anomalias geoquímicas naturais na região, como elevadas concentrações de fluoreto e de salinidade (Vidal, 2002; Hypolito et al., 2010; Ezaki, 2011).
Trata-se de região que constitui uma lacuna em termos de estudos hidrogeológicos efetuados pelo Instituto Geológico-SMA numa faixa que se estende desde a região sul de Sorocaba até ao norte de Campinas com a finalidade de subsidiar o planejamento territorial, podendo ser citados os trabalhos de Sorocaba (Instituto Geológico, 1990); Folha de Salto de Pirapora (Instituto Geológico, 1990); Itu (Instituto Geológico, 1991); Campinas (Instituto Geológico, 1993); Média Bacia do Rio Piracicaba (Instituto Geológico, 1995).

Os resultados deste trabalho compõem parte de projeto desenvolvido pelo Instituto Geológico (2012), e auxiliaram na identificação de áreas potenciais de restrição e controle ao uso da água subterrânea no que se refere ao potencial de contaminação das águas. 


\section{2 Área, materiais e métodos}

\subsection{Contexto geológico da área}

A área situa-se na borda leste da Bacia Sedimentar do Paraná, na Depressão Periférica Paulista, onde sedimentos permocarboníferos do Grupo Tubarão recobrem o embasamento cristalino pré-cambriano representado, na região, por rochas de médio a alto grau metamórfico do Complexo Amparo, que correspondem a gnaisses com intercalações de quartzitos, xistos, anfibolitos, gonditos e metaultrabasitos (Almeida et al., 1981; Bistrichi et al., 1981; Sachs,1999a, 1999b; Neves, 2005). Ainda compondo o embasamento, ocorrem intrusões granitóides encaixadas nos gnaisses e migmatitos, dentre as quais se destaca o Complexo Granitóide Itu ou Granito Itu (Galembeck, 1997).

Na região, as rochas sedimentares do Grupo Tu- barão subdividem-se em duas unidades, o Subgrupo Itararé e a Formação Tatuí. O Subgrupo Itararé corresponde à unidade basal, mais espessa do Grupo Tubarão, e foi depositado em ambientes lacustres, deltaicos e marinhos presentes na interface entre o continente e a plataforma marinha, sob influência glacial, periglacial e interglacial (Stevaux et al., 1987; Zalán et al., 1991; Petri \& Pires, 1992; Santos, 1996, Salvetti, 2005). Constitui-se de litotipos bastante variáveis e descontínuos representados por intercalações e associações de arenitos, siltitos, folhelhos, argilitos, diamictitos e ritmitos, com variação e interdigitação faciológica, tanto horizontal como verticalmente. A totalidade dos poços tubulares construídos e que explotam as águas do Grupo Tubarão correspondem a esta unidade.

Ocorrem também rochas intrusivas básicas (sills ou diques) da Formação Serra Geral (Grupo São Bento) e materiais de cobertura cenozóicos (Fig. 2).

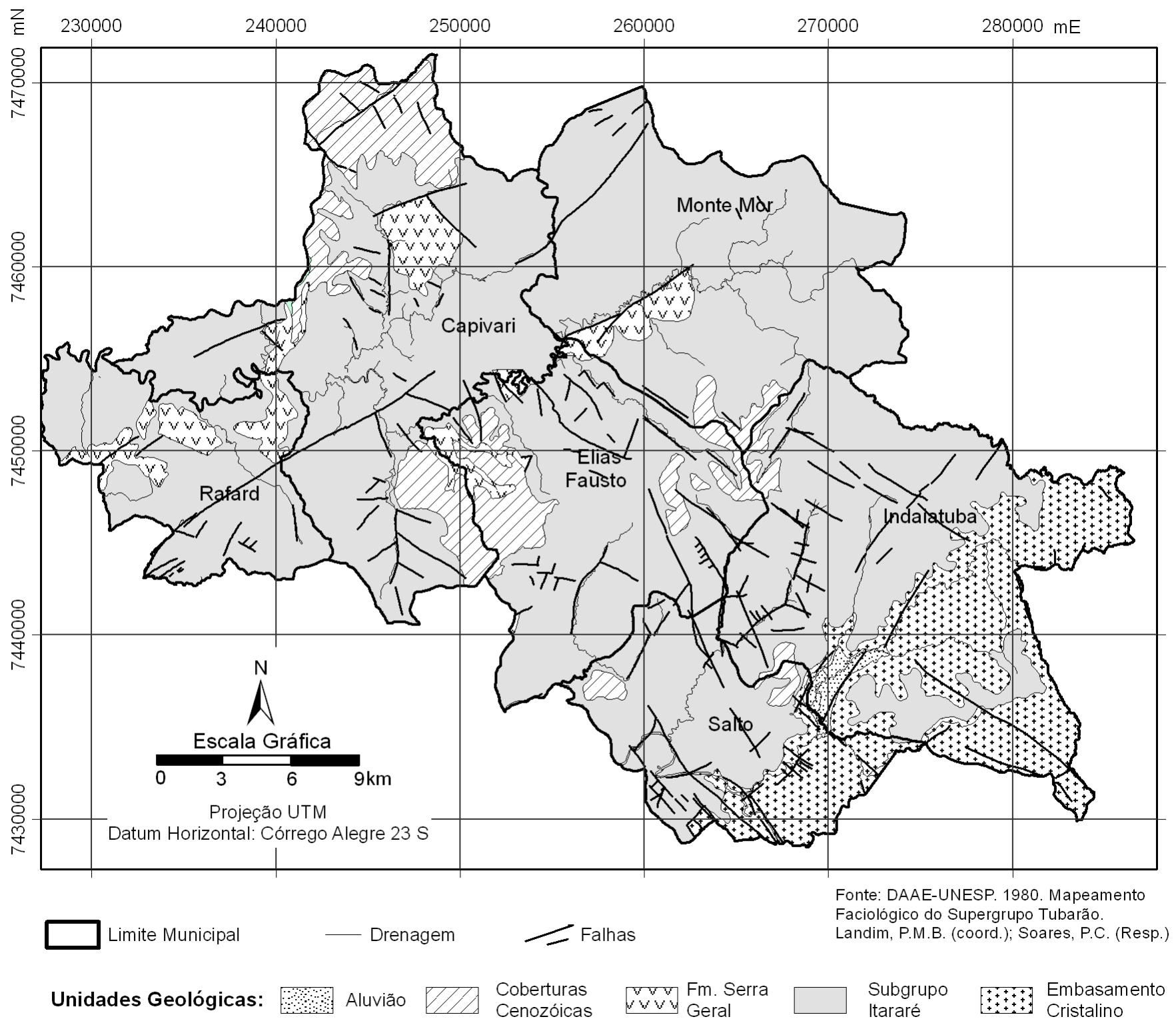

Figura 2. Mapa geológico simplificado da área de estudo. 
Estas unidades correspondem aos principais sistemas aquíferos da região que foram denominados de Tubarão, Cristalino e Diabásio. O Sistema Aquífero Tubarão (SAT) consiste na principal fonte de abastecimento de água subterrânea e é um aquífero livre com características locais de semi-confinado devido à disposição irregular de camadas e lentes de sedimentos finos (lamito, siltito, folhelho) em meio a sedimentos clásticos grossos (arenito, conglomerado e diamictito), conforme seu ambiente sedimentar de deposição. Isolamento de corpos arenosos, baixa permeabilidade devido presença de lentes de argila e baixa porosidade, dificultam o fluxo vertical da água, conferindo-lhe características anisotrópicas (Departamento de Águas e Energia Elétrica,1981a, 1981b).

O SAT apresenta produtividade limitada, contendo localmente áreas de maior potencial. A capacidade específica mediana é de $0,125 \mathrm{~m}^{3} / \mathrm{h} / \mathrm{m}$ e a vazão de 7 $\mathrm{m}^{3} / \mathrm{h}$ para poços situados fora dos lineamentos de drenagem, na região metropolitana de Campinas (RMC) (Pereira, 1997). 0 fluxo regional das águas subterrâneas é de leste para oeste, da borda para o interior da Bacia do Paraná, podendo apresentar direção N-S próximo a vales dos principais rios da região (Rio Capivari, Rio Tietê e Rio Sorocaba) (Vidal, 2002).

O Sistema Aquífero Cristalino (SAC) ocorre na porção leste dos municípios de Salto e Indaiatuba e corresponde ao embasamento do SAT. 0 armazenamento e a circulação das águas subterrâneas ocorrem através das fraturas das rochas e/ou através do manto de alteração das mesmas. Pelos estudos realizados por Departa- mento de Águas e Energia Elétrica(1981b), na Região Administrativa de Sorocaba, a capacidade específica mediana deste aquífero é de $0,22 \mathrm{~m}^{3} / \mathrm{h} / \mathrm{m}$ nos poços locados em lineamentos de drenagem. Fora dos lineamentos de drenagem a mediana é de $0,038 \mathrm{~m}^{3} / \mathrm{h} / \mathrm{m}$. Pereira (1997) encontrou na RMC capacidades específicas mediana e média de $0,1 \mathrm{~m}^{3} / \mathrm{h} / \mathrm{m}$ (intervalos de 0,05 a 0,5 ) e $0,28 \mathrm{~m}^{3} / \mathrm{h} / \mathrm{m}$, respectivamente, e vazões mediana e média de $5,2 \mathrm{~m}^{3} / \mathrm{h} \mathrm{e} 7,3 \mathrm{~m}^{3} / \mathrm{h}$. 0 escoamento da água subterrânea regional deste sistema aquífero na Bacia do Rio Jundiaí dirige-se para oeste, rumo à Bacia Sedimentar (Neves, 2005).

O terceiro sistema é o Aquífero Diabásio, composto por rochas intrusivas básicas (principalmente, diabásios) e ocorre de forma irregular e restrita. Por ser pouco explotado (menos de $1 \%$ dos poços) na área não foi avaliado neste estudo.

\subsection{Materiais e métodos}

Durante as campanhas de levantamento de campo foram cadastrados 1262 poços tubulares, dos quais se selecionaram 41 poços para amostragem de água e análise química, priorizando-se aqueles em funcionamento, de abastecimento público ou particulares, situados na proximidade de estabelecimentos industriais. Dentre estes poços, 7 explotam o Aquífero Cristalino, 28 o Aquífero Tubarão, 2 correspondem a poços mistos (Tubarão/Cristalino e Tubarão/Diabásio) e 7 explotam aquífero não definido (Fig. 3).

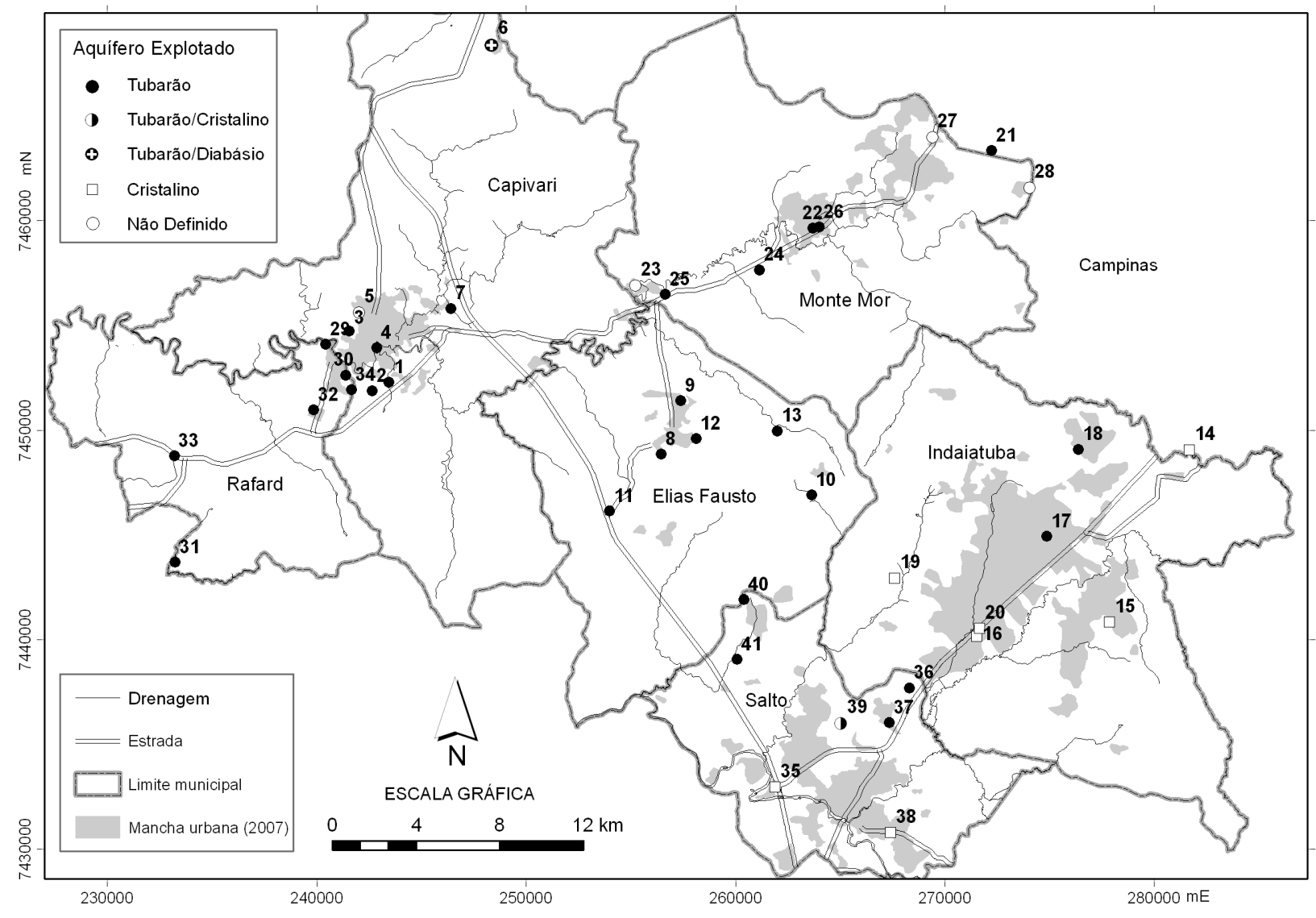

Figura 3. Localização dos poços tubulares profundos amostrados. 
Amostras de água subterrânea foram coletadas na saída do poço, após período de 5 a 10 min de bombeamento e acondicionadas em frascos plásticos de polietileno de alta densidade (PEAD). Logo após a coleta, foram analisados in situ os parâmetros $\mathrm{pH}$, Eh (potencial de óxido-redução), temperatura, utilizando eletrodos de vidro e combinado de platina e condutividade elétrica (DIGIMED). A alcalinidade foi determinada por titulometria, conforme Hypolito et al. (2009).

Em seguida, as amostras foram filtradas (filtro de acetato de 0,45 $\mu \mathrm{m}$ ), armazenadas em frascos de PEAD e mantidas à temperatura inferior a $4^{\circ} \mathrm{C}$ para encaminhamento ao laboratório de análises químicas. A preservação das amostras foi realizada no Laboratório de Hidrogeologia e Hidroquímica do Instituto de Geociências e Ciências Exatas, UNESP, Rio Claro. Os parâmetros químicos analisados foram: $\mathrm{Na}^{+}, \mathrm{K}^{+}, \mathrm{Cl}^{-}, \mathrm{SO}_{4}{ }^{2-}$, $\mathrm{NO}_{3}$; $\mathrm{F}^{-}$(cromatografia iônica); $\mathrm{Ca}^{2+}, \mathrm{Mg}^{2+}, \mathrm{Fe}_{\text {(total) }}, \mathrm{Mn}^{4+}$, $\mathrm{Al}^{3+}$ (espectrometria de emissão atômica com fonte de plasma de argônio indutivo ICP-AES). A alcalinidade em laboratório foi determinada por titulometria potenciométrica. As análises basearam-se no Standard Methods for the Examination of Water and Wastewater (American Health Association/ American Water Works Association/ Water Environment Federation, 1995).

Cerca de $50 \mathrm{~mL}$ de amostras de água foram coletadas em duplicata e armazenadas em frasco de vidro âmbar à temperatura ambiente para análises de isótopos ${ }^{18} \mathrm{O}$ e deutério, efetuadas no Laboratório de Isótopos Estáveis do Instituto de Geociências, USP, São Paulo.

Os íons maiores foram selecionados de modo a possibilitar o cálculo do balanço iônico e a classificação química das águas subterrâneas. 0 balanço iônico (erro em \%) foi calculado conforme procedimentos propostos por Custódio \& Llamas (1983).

Para classificação dos tipos hidroquímicos os dados foram tratados e lançados em Diagramas de Piper e de Stiff, com recurso do programa AcquaChem 5.1 da Schlumberger Water Services.

Os valores de sólidos totais dissolvidos foram calculados pela razão: STD calculado / Condutividade Elétrica $=0,65$. 0 fator de conversão 0,65 foi obtido através da média de valores (STD/CE) extraídos de relatórios de poços da região.

Para avaliar a qualidade das águas foram considerados os resultados destas 41 amostras, além de dados coletados em 470 laudos referentes a 360 poços outorgados. Parâmetros como nitrato, fluoreto, ferro, manganês e total de sólidos dissolvidos foram utilizados como indicadores da qualidade das águas dos aquíferos. Os dados de concentração destes parâmetros de água foram representados espacialmente utilizando-se o programa ArcView 10.1 da ESRI (versão de 2012).

\section{Resultados e discussões}

As tabelas 1 e 2 contêm informações dos poços tubulares amostrados na região entre Indaiatuba e
Rafard e resultados das análises químicas a partir dos quais foram identificados os tipos hidroquímicos dominantes para os aquíferos estudados - Cristalino, Tubarão e sistema misto Tubarão/Cristalino.

\subsection{Hidroquímica}

No Aquífero Cristalino as águas são do tipo bicarbonatada sódica, cálcica ou mista (Na-Ca- $\mathrm{HCO}_{3}, \mathrm{Ca}-$ $-\mathrm{Na}-\mathrm{HCO}_{3}$ ), com proporções variáveis de $\mathrm{Na}^{+}, \mathrm{Ca}^{2+} \mathrm{e}$ $\mathrm{Mg}^{2+}$ (Fig. 4). Esta classificação é concordante com as de Campos (1993) e Diogo et al. (1981). O Departamento de Águas e Energia Elétrica (1981b) classificou as águas do Aquífero Cristalino como predominantemente bicarbonatadas cálcicas (89\%) e bicarbonatadas sódicas (11\%), considerando-se dados de 18 poços da Região Administrativa de Sorocaba.

As amostras dos poços №16, 19 e 35 sofrem influência da cobertura sedimentar (com pequena espessura variando de 25 a $48 \mathrm{~m}$ ) sobreposta ao granito na sua composição química, podendo ocorrer ocasionalmente alguns casos de águas enriquecidas em sulfato (Na-Ca- $\mathrm{HCO}_{3}-\mathrm{SO}_{4}$ ). Isto também foi observado por Ezaki (2011) em poços que explotam o Cristalino em Salto (SP).

$0 \mathrm{pH}$ médio das águas do Aquífero Cristalino é de 7,35 variando de 6,3 a 8,1. Suas águas são fracamente mineralizadas, constatado pelos baixos valores de condutividade elétrica com média de $170 \mu \mathrm{S} / \mathrm{cm}$, também condizentes com valores encontrados pelo Departamento de Águas e Energia Elétrica (1981b), inferiores a $260 \mu \mathrm{S} / \mathrm{cm}$. Um poço em Salto (SA-1) apresentou valor elevado de CE $(1306 \mu \mathrm{S} / \mathrm{cm})$ e não foi considerado na média por representar uma anomalia que deverá ser investigada quanto à origem da salinidade.

As águas do Aquífero Tubarão são predominantemente bicarbonatadas sódicas ( $\mathrm{Na}-\mathrm{HCO}_{3}, \mathrm{Na}-\mathrm{Ca}-\mathrm{HCO}_{3}$ ), podendo ocorrer águas bicarbonatadas cálcicas (Ca-Na- $\mathrm{HCO}_{3}$, Ca-Mg-Na- $\mathrm{HCO}_{3}$ ) e magnesianas (Mg-Ca$\left.-\mathrm{HCO}_{3}\right)$ e águas sulfatadas $\left(\mathrm{Na}-\mathrm{HCO}_{3}-\mathrm{SO}_{4}, \mathrm{Na}-\mathrm{Ca}-\mathrm{HCO}_{3}\right.$ $-\mathrm{SO}_{4}$ ) (Fig. 4). Estas características são concordantes com dados regionais obtidos a partir de 30 poços dos estudos do Departamento de Águas e Energia Elétrica (1981b) para a Região Administrativa de Sorocaba que são, em sua maioria, bicarbonatadas sódicas $(66,7 \%)$, seguidas de bicarbonatadas cálcicas ou magnesianas (30\%) e, em pequena proporção (3,3 \%), cloretadas sódicas. Campos (1993) constatou tais características e teores mais elevados de cloretos e sulfatos em relação ao Aquífero Cristalino.

Os valores de pH variam de 6,2 a 9,6 e a média é de 8,15 denotando característica alcalina. Companhia de Tecnologia de Saneamento Ambiental de São Paulo (2007) também registrou $\mathrm{pH}$ alcalino com valor médio em torno de 9,0. Diniz (1990) averiguou pH das águas entre 7,0 e 9,7 na região do Médio Tietê (SP). 
Tabela 1. Dados dos poços tubulares amostrados e resultados físico-químicos das águas subterrâneas da região estudada.

\begin{tabular}{|c|c|c|c|c|c|c|c|c|c|c|}
\hline № & Amostra & $\begin{array}{c}\text { № } \\
\text { Poço } \\
\text { IG }\end{array}$ & $\begin{array}{l}\text { UTME } \\
(\mathrm{m})\end{array}$ & UTMN (m) & Aquífero & $\begin{array}{l}\text { Prof. } \\
\text { (m) }\end{array}$ & $\begin{array}{c}\mathrm{CE}(\mu \mathrm{S} / \\
\mathrm{cm})\end{array}$ & $\mathrm{pH}$ & $\begin{array}{l}\text { Tempera- } \\
\text { tura }\left({ }^{\circ} \mathrm{C}\right)\end{array}$ & $\begin{array}{l}\text { Classificação de } \\
\text { Piper }\end{array}$ \\
\hline 1 & CAP - 1 & 1675 & 243426 & 7452292 & $\mathrm{~T}$ & 301 & 321 & 8.3 & 25,2 & Na-HCO3-SO4 \\
\hline 2 & CAP - 2 & 1703 & 242620 & 7451888 & $\mathrm{~T}$ & 300 & 274 & 7,8 & 25,1 & $\mathrm{Na}-\mathrm{Ca}-\mathrm{HCO} 3$ \\
\hline 3 & CAP - 3 & 355 & 241540 & 7454750 & $\mathrm{~T}$ & 300 & 259 & 8,3 & 25,0 & Na-HCO3 \\
\hline 4 & CAP - 4 & 1674 & 242836 & 7453930 & $\mathrm{~T}$ & 292 & 271 & 7,9 & 24,6 & $\mathrm{Na}-\mathrm{HCO} 3$ \\
\hline 5 & CAP - 5 & 860 & 242010 & 7455622 & ND & 300 & 286 & 7,8 & 23,8 & Na-Ca-HCO3 \\
\hline 6 & CAP - 6 & 584 & 248340 & 7468375 & TD & 400 & 311 & 9,6 & 28,8 & Na-HCO3-CO3 \\
\hline 7 & CAP - 7 & 918 & 246394 & 7455822 & $\mathrm{~T}$ & 137 & 308 & 6,7 & 25,2 & Ca-Na-HCO3 \\
\hline 8 & $\mathrm{EF}-1$ & 4207 & 256427 & 7448870 & $\mathrm{~T}$ & 320 & 299 & 7,9 & 22,2 & Na-Ca-HCO3 \\
\hline 9 & $\mathrm{EF}-2$ & 2937 & 257363 & 7451410 & $\mathrm{~T}$ & 252 & 255 & 8,4 & 25,2 & Na-HCO3 \\
\hline 10 & $\mathrm{EF}-3$ & 4213 & 263616 & 7446913 & $\mathrm{~T}$ & 172 & 284 & 7,9 & 24,0 & $\mathrm{Ca}-\mathrm{Na}-\mathrm{HCO} 3$ \\
\hline 11 & $\mathrm{EF}-4$ & 4182 & 253970 & 7446139 & $\mathrm{~T}$ & 104 & 54 & 6,2 & 26,0 & $\mathrm{Na}-\mathrm{HCO} 3$ \\
\hline 12 & $E F-5$ & 4191 & 258096 & 7449600 & $\mathrm{~T}$ & 102 & 356 & 7,5 & 24,9 & $\mathrm{Ca}-\mathrm{Na}-\mathrm{HCO} 3$ \\
\hline 13 & $\mathrm{EF}-6$ & 3366 & 261988 & 7449970 & $\mathrm{~T}$ & 156 & 219 & 8,2 & 25,2 & $\mathrm{Na}-\mathrm{Ca}-\mathrm{HCO} 3$ \\
\hline 14 & IN - 1 & 3523 & 281697 & 7449060 & $\mathrm{C}$ & 220 & 188 & 7,6 & 23,9 & Na-Ca-HCO3 \\
\hline 15 & IN - 2 & 4345 & 277878 & 7440847 & $\mathrm{C}$ & 80 & 291 & 7,1 & 23,0 & Ca-Na-Mg-H \\
\hline 16 & IN -3 & 3668 & 271521 & 7440175 & $\mathrm{C}$ & 250 & 212 & 8,1 & 26,6 & $\mathrm{Na}-\mathrm{HCO} 3$ \\
\hline 17 & IN -4 & 3854 & 274859 & 7444935 & $\mathrm{~T}$ & 282 & 291 & 7,9 & 25,7 & Na-Ca-HCO3 \\
\hline 18 & IN -5 & 3929 & 276362 & 7449094 & $\mathrm{~T}$ & 74 & 175 & 7,5 & 24,1 & Ca-Na-HCO3 \\
\hline 19 & IN -6 & 3867 & 267613 & 7442943 & $\mathrm{C}$ & 144 & 28,5 & 6,3 & 24,9 & $\mathrm{Na}-\mathrm{Ca}-\mathrm{HCO} 3-\mathrm{CO} 3$ \\
\hline 20 & IN - 7 & 4305 & 271659 & 7440546 & $\mathrm{C}$ & 270 & 107 & 6,9 & 25,6 & Ca-Na-Mg-HCO3 \\
\hline 21 & MM - 1 & 4430 & 272230 & 7463350 & $\mathrm{~T}$ & & 156 & 8,0 & & Na-HCO3 \\
\hline 22 & MM - 2 & 569 & 263676 & 7459650 & $\mathrm{~T}$ & 315 & 371 & 9,2 & 26,5 & $\mathrm{Na}-\mathrm{HCO} 3$ \\
\hline 23 & MM - 3 & 3926 & 255212 & 7456920 & ND & & 406 & 9,0 & 26,4 & $\mathrm{Na}-\mathrm{HCO} 3$ \\
\hline 24 & MM - 4 & 1448 & 261129 & 7457662 & $\mathrm{~T}$ & 186 & 209 & 8,9 & 26,0 & $\mathrm{Na}-\mathrm{HCO} 3$ \\
\hline 25 & MM - 5 & 570 & 256632 & 7456483 & $\mathrm{~T}$ & 236 & 442 & 9,1 & 27,3 & $\mathrm{Na}-\mathrm{HCO} 3$ \\
\hline 26 & MM - 6 & 4154 & 263996 & 7459708 & $\mathrm{~T}$ & 150 & 345 & 9,2 & 27,4 & Na-HCO3 \\
\hline 27 & MM - 7 & 1441 & 269397 & 7463997 & ND & & 97 & 6,3 & 26,1 & Na-Ca-HCO3 \\
\hline 28 & MM - 8 & 1648 & 274017 & 7461580 & ND & & 197 & 6,6 & 24,0 & Na-Ca-HCO3 \\
\hline 29 & $\mathrm{RA}-1$ & 317 & 240416 & 7454105 & $\mathrm{~T}$ & 251 & 415 & 8,8 & 26,9 & $\mathrm{Na}-\mathrm{HCO} 3$ \\
\hline 30 & RA - 2 & 1081 & 241362 & 7452632 & $\mathrm{~T}$ & 181 & 299 & 9,1 & 26,8 & $\mathrm{Na}-\mathrm{HCO} 3$ \\
\hline 31 & $\mathrm{RA}-3$ & 315 & 233205 & 7443705 & $\mathrm{~T}$ & 160 & 260 & 8,0 & 22,9 & Na-Ca-HCO3 \\
\hline 32 & $\mathrm{RA}-4$ & 1834 & 239832 & 7450975 & $\mathrm{~T}$ & 340 & 222 & 7,0 & 25,5 & Ca-Mg-Na-HCO3 \\
\hline 33 & $\mathrm{RA}-5$ & 1830 & 233173 & 7448782 & $\mathrm{~T}$ & 120 & 230 & 9,2 & 26,0 & $\mathrm{Na}-\mathrm{HCO} 3-\mathrm{CO} 3$ \\
\hline 34 & $\mathrm{RA}-6$ & 1079 & 241641 & 7451944 & $\mathrm{~T}$ & 176 & 227 & 8,7 & 26,5 & $\mathrm{Na}-\mathrm{HCO} 3$ \\
\hline 35 & SA - 1 & 4444 & 261,890 & 7432970 & $\mathrm{C}$ & 198 & 1306 & 7,8 & 24,4 & Ca-Na-SO4 \\
\hline 36 & SA - 2 & 4145 & 268,300 & 7437700 & $\mathrm{~T}$ & 150 & 309 & 7,8 & 24,0 & $\mathrm{Na}-\mathrm{Ca}-\mathrm{HCO} 3-\mathrm{SO} 4$ \\
\hline 37 & $S A-3$ & 948 & 267331 & 7436051 & $\mathrm{~T}$ & 200 & 335 & 8,2 & 25,0 & $\mathrm{Na}-\mathrm{Ca}-\mathrm{HCO} 3-\mathrm{SO} 4$ \\
\hline 38 & SA -4 & 3821 & 267419 & 7430794 & $\mathrm{C}$ & 270 & 195 & 7,7 & 24,9 & Ca-Na-HCO3 \\
\hline 39 & $S A-5$ & 3665 & 265030 & 7435994 & $\mathrm{TC}$ & 282 & 320 & 8,6 & 27,3 & $\mathrm{Na}-\mathrm{HCO} 3$ \\
\hline 40 & SA - 6 & 4129 & 260393 & 7441919 & $\mathrm{~T}$ & 190 & 274 & 8,6 & 25,0 & $\mathrm{Na}-\mathrm{HCO} 3$ \\
\hline 41 & $S A-7$ & 952 & 260063 & 7439064 & $\mathrm{~T}$ & 120 & 237 & 7,7 & 25,6 & Ca-Na-HCO3 \\
\hline
\end{tabular}

Aquífero: T=Tubarão; C=Cristalino; TC=Tubarão/Cristalino; ND=Não Definido 
Tabela 2. Resultados analíticos químicos (concentração em mg/L) e isotópicos (em \%o) das águas subterrâneas da região estudada.

\begin{tabular}{|c|c|c|c|c|c|c|c|c|c|c|c|c|c|c|c|}
\hline & $\mathrm{HCO}_{3}^{-}$ & $\mathrm{CO}_{3}{ }^{2-}$ & $\mathrm{SO}_{4}{ }^{2-}$ & $\mathrm{Cl}^{-}$ & $\mathrm{F}^{-}$ & $\mathrm{NO}_{3}^{-}$ & $\mathrm{Na}^{+}$ & $\mathrm{Ca}^{2+}$ & $\mathrm{Mg}^{2+}$ & $\mathrm{K}^{+}$ & $\mathrm{Al}^{3+}$ & $\mathrm{Mn}^{2+}$ & $\mathrm{Fe}_{\mathrm{t}}$ & $\delta \mathrm{D}$ & $\delta^{18} \mathrm{O}$ \\
\hline $\mathrm{N}^{\circ}$ & & & $250,00^{*}$ & $250,00^{*}$ & $1,50^{*}$ & $45,00 *$ & $200,00^{*}$ & & & & $0,20 *$ & $0,10^{*}$ & $0,30^{*}$ & & \\
\hline 1 & 154 & $<2,00$ & 36,1 & 3,51 & 1,54 & 0,46 & 60,6 & 10,4 & 1,01 & 0,3 & $<0,010$ & $<0,010$ & $<0,010$ & $-61,56$ & $-8,25$ \\
\hline 2 & 181 & $<2,00$ & 2,25 & 0,51 & 0,06 & 0,86 & 42,5 & 25,5 & 1,70 & 1,03 & $<0,010$ & $<0,010$ & $<0,010$ & $-51,08$ & $-6,96$ \\
\hline 3 & 163 & $<2,00$ & 7,53 & 0,57 & 0,1 & 0,3 & 50,4 & 8,65 & 1,44 & 0,34 & $<0,010$ & $<0,010$ & $<0,010$ & $-60,87$ & $-8,25$ \\
\hline 4 & 148 & $<2,00$ & 12,1 & 5,28 & 0,17 & 3,95 & 58,5 & 3,36 & 0,78 & 0,23 & $<0,010$ & $<0,010$ & $<0,010$ & $-55,93$ & $-7,75$ \\
\hline 5 & 189 & $<2,00$ & 5,02 & 1,43 & $<0,02$ & $<0,10$ & 34,7 & 28,6 & 1,75 & 0,69 & $<0,010$ & 0,018 & $<0,010$ & $-52,4$ & $-7,28$ \\
\hline 6 & 130 & 36,7 & 2,78 & 0,38 & 0,37 & $<0,10$ & 72,4 & 1,95 & $\begin{array}{c}< \\
0,025\end{array}$ & $<0,20$ & 0,014 & $<0,010$ & $<0,010$ & $-60,87$ & $-8,15$ \\
\hline 7 & 143 & $<2,00$ & 21,10 & 10,2 & $<0,02$ & 9,03 & 23,4 & 34,3 & 4,35 & 1,84 & $<0,010$ & 0,036 & $<0,010$ & $-44,75$ & $-6,33$ \\
\hline 8 & 194 & $<2,00$ & 5,32 & 0,71 & 0,08 & 0,43 & 35,6 & 27,3 & 3,89 & 2,07 & $<0,010$ & 0,36 & 0,13 & $-53,00$ & $-7,59$ \\
\hline 9 & 164 & $<2,00$ & 6,32 & 0,33 & 0,05 & 0,28 & 57,9 & 2,2 & 0,3 & 0,3 & $<0,010$ & $<0,010$ & $<0,010$ & $-63,44$ & $-8,96$ \\
\hline 10 & 188 & $<2,00$ & 2,40 & 0,43 & 0,02 & 0,26 & 29,7 & 32,3 & 6,17 & 2,13 & $<0,010$ & 0,13 & 0,046 & $-48,46$ & $-7,12$ \\
\hline 11 & 30,1 & $<2,00$ & 1,07 & 0,97 & 0,03 & 1,39 & 6,63 & 1,47 & 1,19 & 2,6 & 0,019 & $<0,010$ & 0,011 & $-49,8$ & $-7,04$ \\
\hline 12 & 245 & $<2,00$ & 4,33 & 0,08 & 0,12 & $<0,10$ & 20,2 & 45,6 & 8,71 & 1,2 & $<0,010$ & 0,62 & $<0,010$ & $-46,51$ & $-7,04$ \\
\hline 13 & 145 & $<2,00$ & 3,12 & 0,21 & 0,06 & $<0,10$ & 25,8 & 17,6 & 3,29 & 1,71 & $<0,010$ & 0,11 & $<0,010$ & $-53,88$ & $-7,83$ \\
\hline 14 & 91,4 & $<2,00$ & 11,40 & 5,42 & 1,41 & 0,3 & 28,9 & 9,44 & 1,91 & $<0,20$ & $<0,010$ & $<0,010$ & $<0,010$ & $-51,56$ & $-7,70$ \\
\hline 15 & 109 & $<2,00$ & 7,28 & 11,3 & 0,29 & 44,5 & 22,3 & 24,7 & 10,2 & 3,18 & $<0,010$ & 0,016 & 0,056 & $-43,68$ & $-6,6$ \\
\hline 16 & 121 & $<2,00$ & 9,35 & 1,21 & 1,72 & $<0,10$ & 40,8 & 7,11 & 0,4 & 0,55 & 0,025 & $<0,010$ & $<0,010$ & $-50,02$ & $-7,4$ \\
\hline 17 & 149 & $<2,00$ & 2,52 & 5,41 & 0,13 & 24,6 & 40,1 & 14,4 & 4,95 & 1,8 & 0,028 & $<0,010$ & $<0,010$ & $-46,86$ & $-7,01$ \\
\hline 18 & 112 & $<2,00$ & 2,43 & 0,21 & 0,08 & $<0,10$ & 12,4 & 20,6 & 2,15 & 1,96 & 0,023 & $<0,010$ & $<0,010$ & $-45,67$ & $-7,11$ \\
\hline 19 & 17,7 & $<2,00$ & 0,15 & 0,02 & $<0,02$ & 0,15 & 2,24 & 1,37 & 0,51 & 2,28 & 0,012 & $<0,010$ & $<0,010$ & $-45,41$ & $-6,92$ \\
\hline 20 & 67,2 & $<2,00$ & 0,16 & 0,16 & 0,05 & 0,96 & 6,87 & 9,59 & 3,09 & 1,62 & 0,016 & $<0,010$ & $<0,010$ & $-42,81$ & $-6,52$ \\
\hline 21 & 103 & $<2,00$ & 3,61 & 0,32 & 0,04 & 0,21 & 32,4 & 2,48 & 0,21 & 0,75 & 0,032 & $<0,010$ & $<0,010$ & & \\
\hline 22 & 192 & 16,60 & 12,30 & 1,72 & 0,29 & 0,67 & 88 & 0,99 & 0,056 & 1,87 & 0,011 & $<0,010$ & $<0,010$ & $-65,39$ & $-8,94$ \\
\hline 23 & 241 & 11,30 & 7,15 & 0,86 & 0,15 & 0,5 & 99,5 & 1,21 & 0,18 & $<0,20$ & $<0,010$ & $<0,010$ & $<0,010$ & $-61,79$ & $-8,90$ \\
\hline 24 & 103 & 13,10 & 4,37 & 0,16 & 0,09 & $<0,10$ & 47,3 & 1,6 & 0,039 & $<0,20$ & $<0,010$ & $<0,010$ & $<0,010$ & $-60,79$ & $-8,70$ \\
\hline 25 & 245 & 22,20 & 8,22 & 1,2 & 0,21 & $<0,10$ & 108 & 1,02 & 0,11 & $<0,20$ & 0,014 & $<0,010$ & $<0,010$ & $-61,83$ & $-8,97$ \\
\hline 26 & 177 & 18,30 & 10,50 & 1,43 & 0,25 & $<0,10$ & 82,1 & 1,02 & 0,033 & $<0,20$ & 0,012 & $<0,010$ & $<0,010$ & $-62,00$ & $-9,14$ \\
\hline 27 & 46 & $<2,00$ & 0,45 & 1,9 & 0,06 & 8,32 & 9,47 & 4,54 & 2,15 & 3,53 & $<0,010$ & 0,01 & $<0,010$ & $-49,55$ & $-6,91$ \\
\hline 28 & 94,7 & $<2,00$ & 1,88 & 11,5 & $<0,02$ & 1,89 & 17,5 & 15,1 & 3,07 & 3,09 & $<0,010$ & $<0,010$ & $<0,010$ & $-49,13$ & $-7,18$ \\
\hline 29 & 234 & 6,98 & 12,80 & 6,64 & 0,25 & $<0,10$ & 97,5 & 1,61 & 0,084 & 1,91 & 0,01 & $<0,010$ & $<0,010$ & $-55,7$ & $-8,04$ \\
\hline 30 & 170 & 8,73 & 9,07 & 1,42 & 0,21 & 8,71 & 69,5 & 1,32 & 0,1 & 0,51 & $<0,010$ & $<0,010$ & $<0,010$ & $-61,93$ & $-9,00$ \\
\hline 31 & 165 & $<2,00$ & 9,64 & 0,9 & 0,10 & $<0,10$ & 35 & 20,3 & 2,63 & 1,11 & $<0,010$ & 0,11 & $<0,010$ & $-58,46$ & $-8,44$ \\
\hline 32 & 126 & $<2,00$ & 0,30 & 8,84 & 0,10 & 0,15 & 11 & 20,9 & 8,38 & 2,01 & $<0,010$ & $<0,010$ & $<0,010$ & $-42,48$ & $-5,56$ \\
\hline 33 & 99,1 & 18,80 & 8,48 & 0,82 & 0,23 & $<0,10$ & 51,1 & 2,29 & 0,33 & $<0,20$ & 0,019 & $<0,010$ & $<0,010$ & $-60,07$ & $-8,76$ \\
\hline 34 & 135 & 6,09 & 2,36 & 0,73 & 0,11 & $<0,10$ & 50,4 & 3,85 & 0,087 & 0,26 & $<0,010$ & $<0,010$ & $<0,010$ & $-54,80$ & $-8,23$ \\
\hline 35 & 103 & $<2,00$ & 469,00 & 95,3 & 2,58 & $<0,10$ & 148 & 132 & 4,52 & 0,53 & 0,03 & 0,021 & $<0,010$ & $-52,07$ & $-7,93$ \\
\hline 36 & 108 & $<2,00$ & 45,40 & 11,4 & 0,54 & $<0,10$ & 29,6 & 24 & 5,09 & 1,58 & 0,029 & $<0,010$ & $<0,010$ & $-48,97$ & $-7,51$ \\
\hline 37 & 131 & $<2,00$ & 38,90 & 9,44 & 3,49 & $<0,10$ & 54,4 & 16,7 & 0,55 & 0,26 & 0,024 & $<0,010$ & $<0,010$ & $-55,85$ & $-8,09$ \\
\hline 38 & 118 & $<2,00$ & 1,67 & 0,69 & 1,26 & $<0,10$ & 16,1 & 18,8 & 3,58 & 0,54 & 0,025 & $<0,010$ & $<0,010$ & $-48,15$ & $-7,31$ \\
\hline 39 & 133 & 2,62 & 22,80 & 5,14 & 7,45 & $<0,10$ & 69,9 & 4,25 & 0,066 & 0,18 & 0,03 & $<0,010$ & $<0,010$ & $-60,89$ & $-9,03$ \\
\hline 40 & 167 & 3,93 & 7,87 & 0,24 & $<0,02$ & $<0,10$ & 63,7 & 2,54 & 0,59 & 0,69 & 0,021 & $<0,010$ & $<0,010$ & $-66,02$ & $-9,73$ \\
\hline 41 & 158 & $<2,00$ & 1,93 & 0,44 & $<0,02$ & $<0,10$ & 18,1 & 20,5 & 5,6 & 2,05 & 0,017 & 0,027 & $<0,010$ & $-47,09$ & $-7,51$ \\
\hline
\end{tabular}

* Limite de Potabilidade (em mg/L) 
A mineralização deste aquífero também é considerada fraca, apesar de apresentar valores mais elevados de condutividade elétrica em relação ao Aquífero Cristalino, variando de 54 a $442 \mu \mathrm{S} / \mathrm{cm}$, com média de $273 \mu \mathrm{S} / \mathrm{cm}$. São águas fracamente salinas, comparáveis com as médias encontradas em outros estudos como os da Região de Campinas (Departamento de Águas e Energia Elétrica, 1981a), onde os valores são inferiores a $350 \mu \mathrm{S} / \mathrm{cm}$, da Região de Sorocaba (Departamento de Águas e Energia Elétrica, 1981b), inferiores a 790 mS/ cm e da Região do Médio Tietê (Diniz, 1990), inferiores a $560 \mu \mathrm{S} / \mathrm{cm}$.

As características das águas dos poços mistos (Tubarão/Cristalino e Tubarão/Diabásio) são mais próximas às do Tubarão (Fig. 4), apresentando pH médio elevado de 9,10 e salinidade mais elevada em relação ao Aquífero Cristalino, com média de 315,5 $\mu \mathrm{S} / \mathrm{cm}$.

Na figura 5 é apresentado o fluxo regional das águas subterrâneas e a distribuição dos principais tipos hidroquímicos na área de estudo.

Em geral os fluxos das águas subterrâneas seguem das porções mais elevadas para as mais rebaixadas topograficamente, onde se situam rios de maior porte da região que correspondem às principais drenagens $\mathrm{e}$ áreas de descarga como o rio Jundiaí (em Indaiatuba); rio Tietê e córrego do Buru (em Salto); rios Capivari e Capivari-Mirim (em Monte Mor, Elias Fausto e Capivari). As altitudes máximas do nível d'água situam-se na porção leste da área de estudo, onde predomina o Aquífero Cristalino, enquanto as porções mais rebaixadas encontram-se a oeste da área, principalmente nas cidades de Capivari e Rafard, nos domínios do Aquífero Tubarão. Os valores de altitude do nível d'água foram extraídos de Instituto Geológico (2012).

Águas bicarbonatadas cálcicas e cálcicas-sódicas são típicas na porção leste da área (Indaiatuba), por estarem associadas, principalmente ao Embasamento Cristalino. Em direção a oeste (Elias Fausto, Monte Mor, Capivari) e a sudoeste (Salto) as águas adquirem composição predominantemente bicarbonatada sódica. Esta variação tende a ocorrer ao longo do fluxo subterrâneo, desde a área de recarga até a descarga, com aumento em sais dissolvidos.

O aumento da concentração de sódio nas águas foi correlacionado por Diogo et al. (1981), Campos (1993), Vidal (2002) e Vidal et al. (2005) ao aumento dos valores de condutividade elétrica, da borda da Bacia Sedimentar do Paraná em direção ao interior no sentido E-W. Vidal et al. (2005) estabeleceram teor de corte de $314 \mu \mathrm{S} / \mathrm{cm}$, acima do qual as águas foram consideradas mineralizadas na área de afloramento do Aquífero Tubarão na porção central do Estado de São Paulo.

$\mathrm{Na}$ área de estudo alguns poços situados na proximidade de drenagens apresentaram valores mais elevados de CE (>300 $\mu \mathrm{S} / \mathrm{cm})$, como por exemplo, os poços no 1 (Capivari); 12 (Elias Fausto); 22, 23, 25 e 26 (Monte Mor); 29 (Rafard); 35 e 37 (Salto), corroborando com este modelo de evolução química das águas em direção às áreas de descarga. Deve-se destacar que o poço 35 é um caso particular de água sulfatada sódica, provavelmente associado a águas de circulação restrita e local do Aquífero Tubarão.

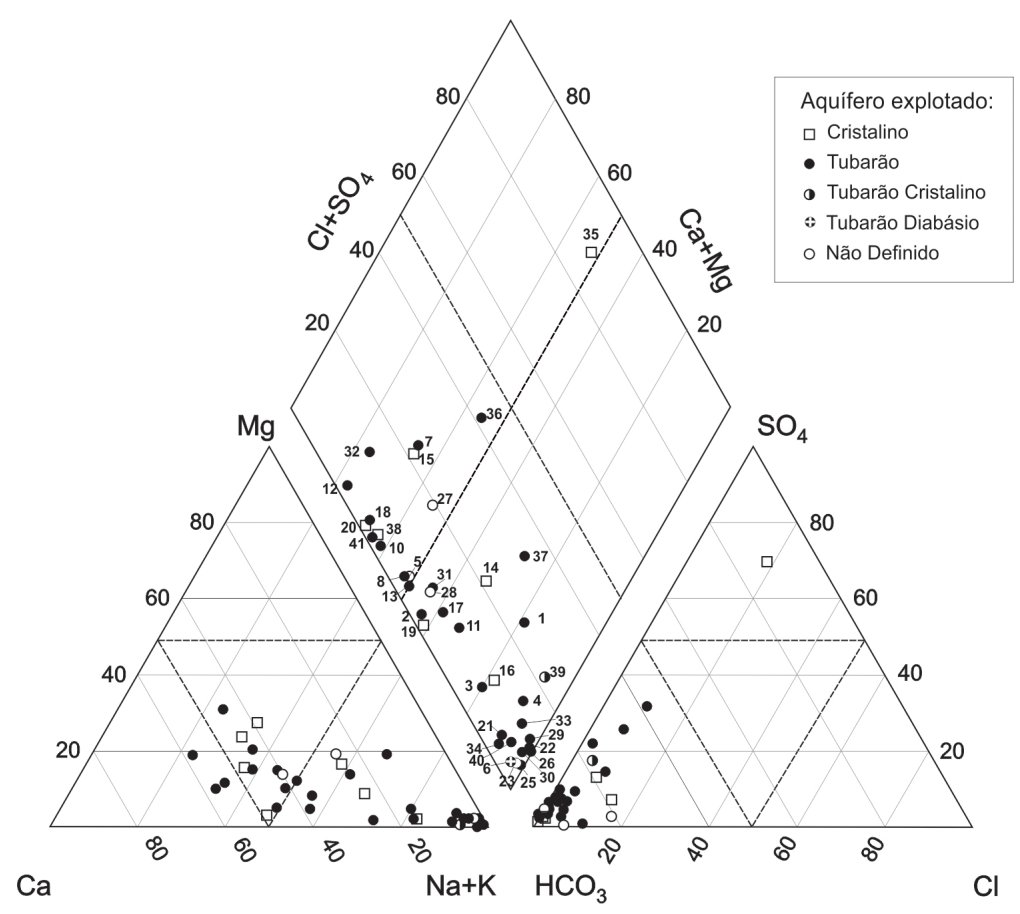

Figura 4. Diagramas de Piper e classificação das águas do Aquífero Tubarão, Cristalino e misto. 


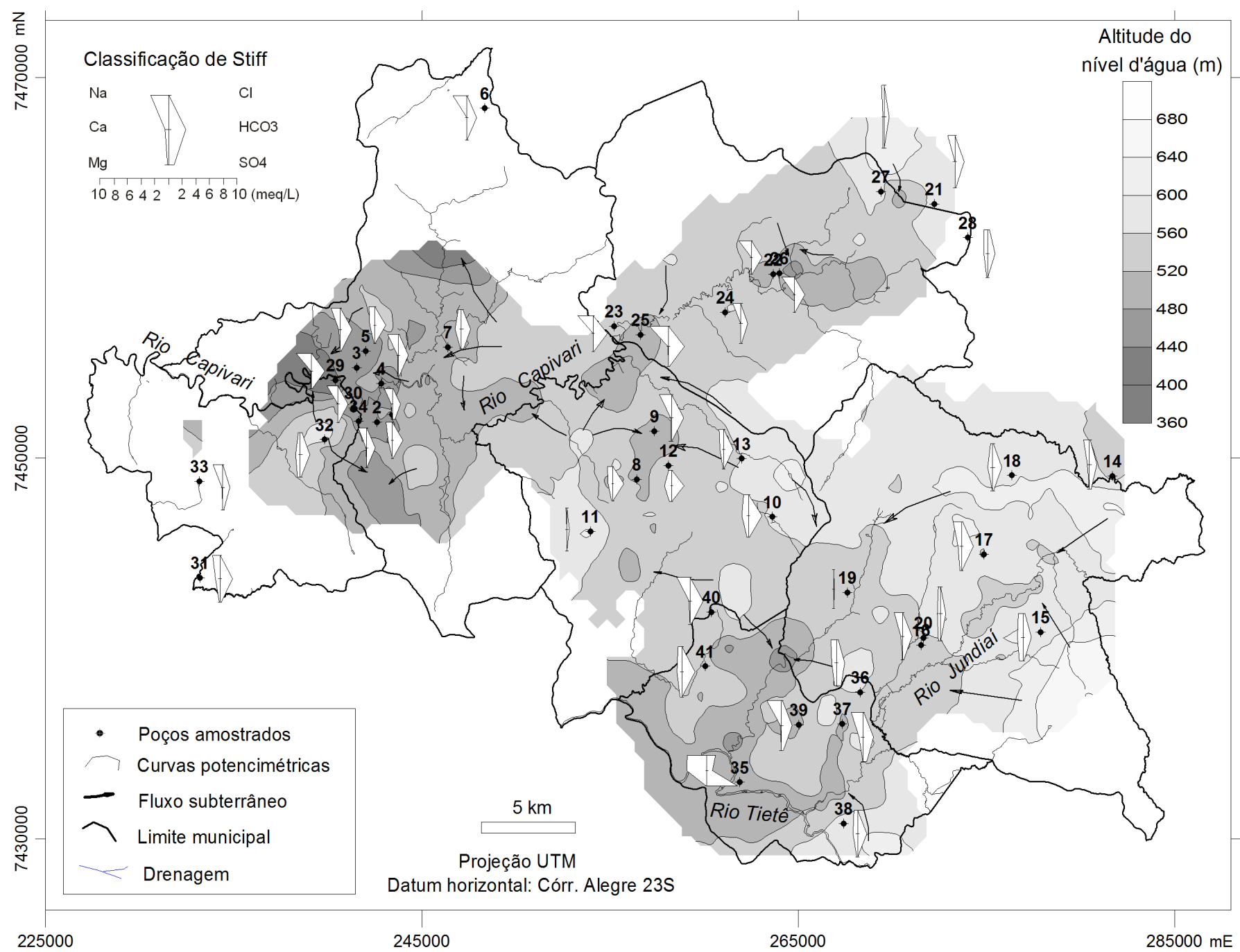

Figura 5. Classificação hidroquímica de águas de poços tubulares nos municípios estudados e potenciometria dos aquíferos.

\subsection{Análises isotópicas}

As concentrações de isótopos estáveis determinadas para amostras de águas do Aquífero Cristalino variaram de $-7,96$ a $-6,52 \%$ para $\delta^{18} 0$ e de $-52,06$ a $-42,81 \%$ para $\delta$ D. Nas amostras do Aquífero Tubarão os valores variaram de $-9,72$ a $-5,56 \%$ para $\delta^{18} 0$ e de $-52,06$ a-42,81 \%o para $\delta \mathrm{D}$ (Tab. 3). Vidal (2002) obteve média similar de $\delta \mathrm{D}(-57,201 \% 0)$ e $\delta^{18} \mathrm{O}(-8,57 \% 0)$ para o Aquífero Tubarão em 16 poços amostrados em Capivari, Monte Mor, Elias Fausto e Rafard.

Tabela 3. Dados estatísticos dos isótopos estáveis de oxigênio e hidrogênio para águas dos Aquíferos Cristalino e Tubarão.

\begin{tabular}{c|c|c|c|c}
\hline \multirow{2}{*}{ Aquífero } & $\begin{array}{c}\text { Número de } \\
\text { amostras }\end{array}$ & valores & $\delta^{18} 0 \% 0$ & $\delta \mathrm{D} \% 0$ \\
\hline \multirow{3}{*}{ Cristalino } & \multirow{3}{*}{6} & mínimo & $-7,93009$ & $-52,06734$ \\
\cline { 3 - 5 } & \multirow{2}{*}{ Tubarão } & máximo & $-6,52199$ & $-42,81188$ \\
\cline { 3 - 5 } & & média & $-7,056023$ & $-47,67174$ \\
\cline { 3 - 5 } & \multirow{2}{*}{27} & desvio padrão & 0,57876 & 3,76138 \\
\hline \multirow{2}{*}{} & & mínimo & $-9,72832$ & $-66,01593$ \\
\cline { 3 - 5 } & & máximo & $-5,56368$ & $-42,47607$ \\
\cline { 3 - 5 } & & média & $-7,768945$ & $-54,93234$ \\
\cline { 3 - 5 } & & desvio padrão & 1,06591 & 6,99327 \\
\hline
\end{tabular}


As correlações entre dados istópicos $\delta \mathrm{D}$ e $\delta^{18} 0$ das águas dos aquíferos Cristalino e Tubarão foram projetadas no diagrama da figura 6 e demonstram que a maior parte das amostras está próxima à linha meteórica global, indicando que a composição das águas subterrâneas pode ser controlada pelas águas meteóricas.

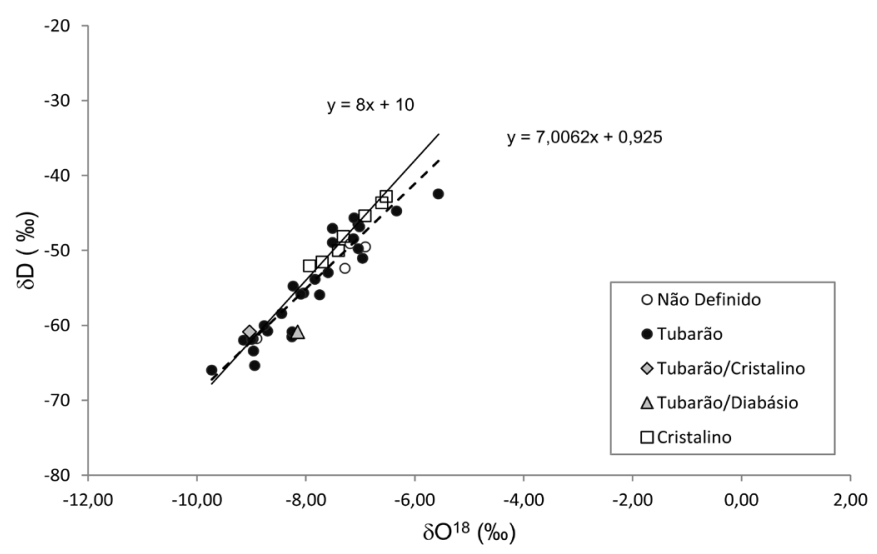

Figura 6. Correlação isotópica entre $\mathrm{D}$ e ${ }^{18} \mathrm{O}$ para os aquíferos Tubarão e Cristalino.

As amostras de água do Aquífero Cristalino são mais enriquecidas em isótopos de $\mathrm{D}$ e de $\mathrm{O}^{18}$. A maior parte das amostras do Aquífero Tubarão (incluindo neste grupo os poços mistos Tubarão/Cristalino, Tubarão/Diabásio e Não definidos) apresenta valores de $\delta^{18} \mathrm{O}$ inferiores a $-7 \%$ o chegando a atingir $<-9 \%$, e valores de $\delta$ D inferiores a $-52 \%$, contudo algumas amostras apresentam o mesmo padrão que as do Cristalino.

Estas amostras com valores mais negativos de $\delta^{18} 0$ e de $\delta \mathrm{D}$ podem indicar que algumas porções do Aquífero Tubarão estão confinadas com a presença de águas de recarga mais antigas e associadas a um período em que o clima era frio. Aravena et al. (1995) encontraram padrão similar em aquífero regional confinado, ao sul de Ontário. Hirata et al. (2011) também associaram baixos valores de $\delta^{18} 0(<-9 \%)$ e de $\delta \mathrm{D}$ a uma zona confinada profunda na Bacia do Paraná com águas muito antigas ( $>10.000$ anos), cuja recarga ocorreu sob período climático frio.

Estas características de água antiga relacionada a porções (semi-)confinadas na área indicam a necessidade de estudos mais aprofundados com o objetivo de avaliar a recarga do Aquífero Tubarão, uma vez que implicam na necessidade de um controle na extração das águas por captações em poços.

\subsection{Qualidade das águas subterrâneas}

Os resultados analíticos de 41 amostras de poços deste Projeto indicaram que alguns parâmetros excedem o valor máximo permitido nas águas para consumo humano, conforme Portaria de Potabilidade No 2914/2011 do Ministério da Saúde (Brasil, 2011): nitrato ( 3 poços), manganês ( 6 poços); fluoreto ( 4 poços); sulfato (1 poço). Reunindo estas informações com os dados de análises químicas de laudos de relatórios de poços, avaliou-se a distribuição das concentrações de ferro, manganês, fluoreto, nitrato e sólidos totais dissolvidos nos poços da área de estudo (Fig. 7). Na tabela 4 são apresentados, sucintamente, dados de concentrações médias e medianas, mínimo e máximo, destes parâmetros utilizados como indicadores de qualidade.

A presença de íons ferro e manganês na água de abastecimento destinada ao uso doméstico é desagradável, mas não apresenta riscos à saúde, uma vez que não há comprovação de efeitos tóxicos quando ingeridos em grandes quantidades.

Sob determinadas condições de $\mathrm{pH}$ prevalecentes no abastecimento de água potável, os sais de Fe (II) são instáveis e reagem com água para formar hidróxidos insolúveis, que conferem cor de ferrugem à água. A água muitas vezes apresenta aparência e gosto intragável, podendo manchar a roupa e utensílios domésticos. 0 manganês têm o mesmo comportamento do ferro, provocando sabor desagradável e manchas de coloração preta quando em concentrações superiores a 0,15 $\mathrm{mg} / \mathrm{L}$.

No sistema de distribuição, os íons de ferro e de manganês podem oxidar e precipitar formando depósitos na rede de distribuição e reduzir gradualmente a vazão através do tubo. Mesmo em concentrações de aproximadamente $0,02 \mathrm{mg} / \mathrm{L}$, o manganês pode formar revestimentos nas tubulações de distribuição de água que podem se desprender como precipitados de cor preta (World Health Organization, 2003).

Tabela 4. Concentrações de $\mathrm{Fe}(\mathrm{t}), \mathrm{Mn}^{2+}, \mathrm{F}^{-}, \mathrm{N}-\mathrm{NO}_{3}$ e STD (mg/L) encontradas na área.

\begin{tabular}{|c|c|c|c|c|c|}
\hline Concentração (mg/L) & $\mathrm{Fe}(\mathrm{t})$ & $\mathrm{Mn}^{2+}$ & $\mathrm{F}^{-}$ & $\mathrm{N}-\mathrm{NO}_{2}^{-}$ & STD \\
\hline Média & 0,14 & 0,08 & 0,61 & $3,53^{3}$ & 201,02 \\
\hline Mediana & 0,05 & 0,02 & 0,20 & 0,49 & 162,82 \\
\hline Mínimo & 0,00 & 0,00 & 0,00 & 0,00 & 16,00 \\
\hline Potabilidade (Portaria No 2914/2011) & 0,30 & 0,10 & 1,50 & 10,00 & 1000,00 \\
\hline Total de poços & 328 & 173 & 220 & 322 & 235 \\
\hline Poços com concentrações acima da potabilidade & $32(9,75 \%)$ & $27(15,60 \%)$ & $25(11,36 \%)$ & $3(0,93 \%)$ & $3(1,3 \%)$ \\
\hline
\end{tabular}



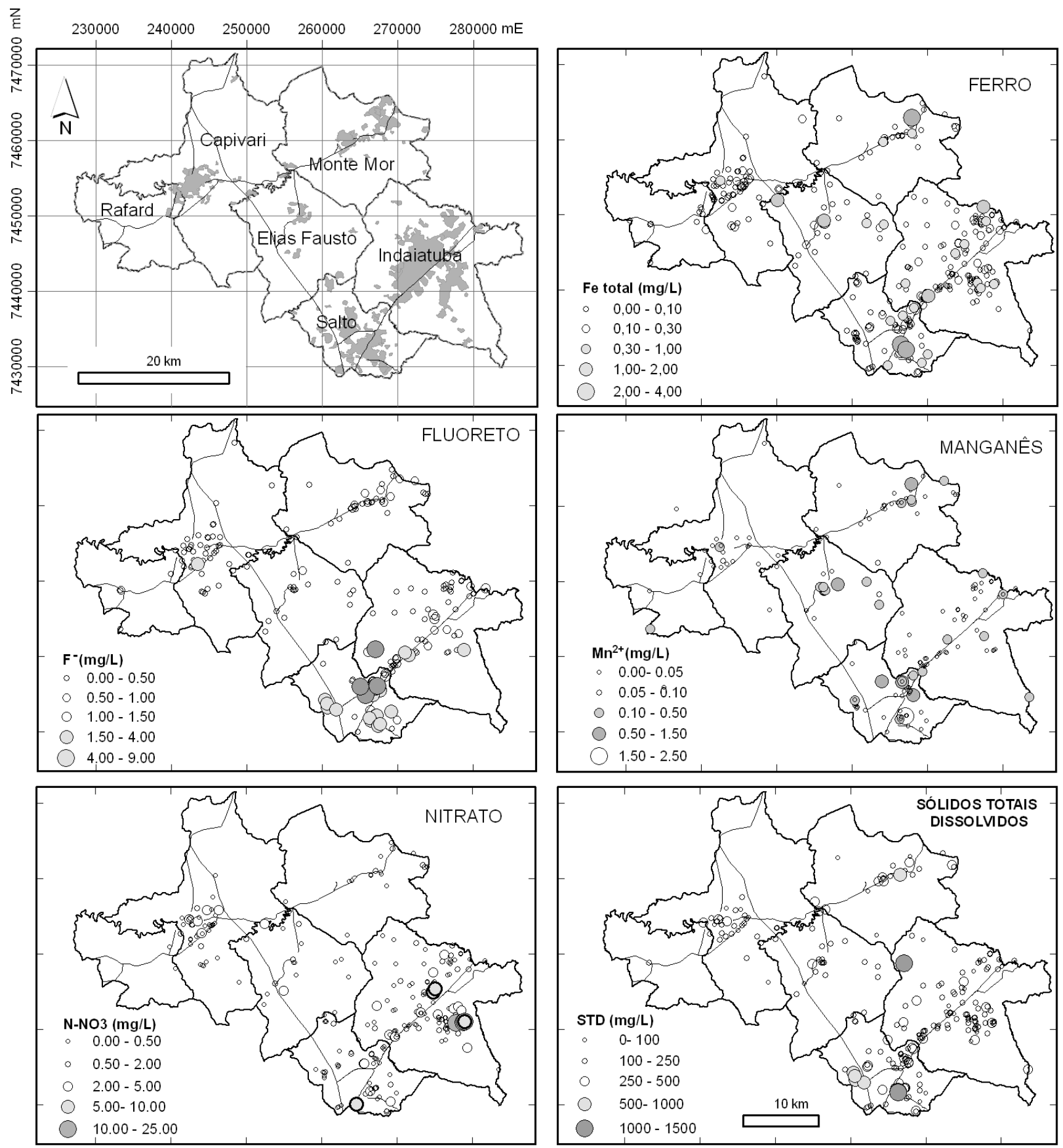

Figura 7. Distribuição das concentrações de ferro, manganês, fluoreto, nitrato e sólidos totais dissolvidos em poços da região entre Indaiatuba e Capivari (SP).

O ferro pode também promover o crescimento de ferro-bactérias que obtêm energia a partir da oxidação do Fe (II) a Fe (III), e, no processo, uma camada viscosa é depositada nas tubulações de distribuição de água, levando contaminação biológica na água para consumo humano (Canadian Council of Resource and Environment Ministers, 1987; World Health Organization, 2003). 0 manganês também pode favorecer o crescimento de certos organismos ("manganês"-bactérias) que causam problemas de sabor, odor e turbidez da água distribuída.

A ocorrência do ferro e do manganês em concentrações elevadas, respectivamente em 9,75 \% e 15,60
\% dos poços da área (Tab. 4), pode estar relacionada às características das formações geológicas da região ou a problemas construtivos do poço.

Em dez poços ocorrem teores de ferro e de manganês acima da potabilidade, dos quais quatro são destinados ao abastecimento público: um em Monte Mor (poço IG n ${ }^{\circ} 4160$ ) com $\mathrm{Fe}=3,22 \mathrm{mg} / \mathrm{L}$ e $\mathrm{Mn}=0,78 \mathrm{mg} / \mathrm{L}$; e três em Elias Fausto (poço IG n ${ }^{\circ} 1637$, com $\mathrm{Fe}=0,94$ $\mathrm{mg} / \mathrm{L}$ e $\mathrm{Mn}=0,21 \mathrm{mg} / \mathrm{L}$; poço IG no 4206, com $\mathrm{Fe}=1,22$ $\mathrm{mg} / \mathrm{L} \mathrm{Mn}=0,21 \mathrm{mg} / \mathrm{L}$; e poço $\mathrm{IG} \mathrm{n} \mathrm{n}^{-} 396$, com $\mathrm{Fe}=0,49$ $\mathrm{mg} / \mathrm{L} \mathrm{Mn}=0,13 \mathrm{mg} / \mathrm{L}$ ).

A presença de íons fluoreto nas águas é considerada benéfica à saúde bucal, na dosagem de $0,7 \mathrm{mg} / \mathrm{L}$, 
podendo variar de 0,6 a $0,8 \mathrm{mg} / \mathrm{L}$, uma vez que o flúor fortalece o esmalte do dente e inibe sua desmineralização, prevenindo à cárie (Companhia de Saneamento Básico do Estado de São Paulo, 2013). A ingestão contínua de águas com concentrações elevadas pode acarretar riscos à saúde, como a doença fluorose esqueletal ou dentária, sendo esta identificada por leves manchas esbranquiçadas no esmalte do dente até manchas castanhas levando a fratura na estrutura dental; pode também ocasionar mal estar, ânsia, vômitos e até a morte quando associada à toxicidade. 0 limite para ingestão em água potável considerado pela Organização Mundial de Saúde é de 1,5 mg/L (World Health Organization, 2006), também adotado pela Portaria № 2914/2011 do Ministério da Saúde.

Alguns exemplos podem ser citados como fontes de fluoreto para as águas como: atividades industriais como cerâmica, produção de alumínio, fertilizantes (rochas fosfáticas), fabricação de sabões e detergentes, preparação de couros, entre outras.

$\mathrm{Na}$ área estudada a origem provável está na alteração e hidrólise de minerais de rocha enriquecidos em flúor, sob condições específicas de pH, temperatura, alcalinidade, etc., do meio por onde a água subterrânea percola. Assim como outros autores, foram constatadas correlações positivas entre as concentrações de fluoreto, valores de $\mathrm{pH}$ superior a 7,5 e teores elevados de sódio. Ezaki (2011) considerou a presença de flúor nas águas subterrâneas como ocorrência natural associada à alteração de argilominerais e micas das rochas sedimentares e de biotitas dos granitos da região de Salto (SP), com teores mais elevados no Aquífero Tubarão em relação ao Cristalino.

Considerando 220 poços levantados na região de estudo, em 11,36 \% o limite de potabilidade de fluoreto foi ultrapassado (Tab. 4), predominando nos municípios de Salto e Indaiatuba em poços particulares, e pontualmente em Capivari num poço de abastecimento público (nº IG 1675) (Fig. 7).

Não há registros de casos de fluorose dentária nos município de Salto e Indaiatuba, uma vez que o abastecimento público dá-se, fundamentalmente por mananciais superficiais.

Outro aspecto relevante na região é a ocorrência de água com sabor amargo/salgado, conforme depoimentos de moradores de Salto e Indaiatuba, que denominam a água subterrânea destes poços como salobra.

A salinidade pode ser avaliada em termos de sólidos totais dissolvidos (STD). A Resolução CONAMA № 357, de 17/03/2005, classifica as águas superficiais no território nacional em: doces - STD $<500$ $\mathrm{mg} / \mathrm{L}$; salobras $-500<\mathrm{STD}<30.000 \mathrm{mg} / \mathrm{L}$; e salgadas - STD>30.000 mg/L. O Padrão de aceitação para consumo humano, segundo Portaria de Potabilidade $\mathrm{N}^{\circ}$ 2914/2011 Ministério da Saúde, é de no máximo 1.000 $\mathrm{mg} / \mathrm{L}$ de total de sólidos dissolvidos.

Menegasse et al. (2003) utilizam como referência o trabalho de Companhia de Saneamento de Minas Ge- rais / Hidrosistemas Engenharia de Recursos Hídricos Ltda (1995) para atribuir qualidade de água para consumo humano e irrigação, conforme faixa de concentração de sólidos totais dissolvidos (mg/L): STD $\leq 150$ $\mathrm{mg} / \mathrm{L}$, Boa; $150 \mathrm{mg} / \mathrm{L}<\mathrm{STD} \leq 500 \mathrm{mg} / \mathrm{L}$, Razoável; 500 $\mathrm{mg} / \mathrm{L}<\mathrm{STD}$, Tolerável; STD > $1000 \mathrm{mg} / \mathrm{L}$, Inaceitável.

Na área estudada, dos 235 poços (Fig. 7), $17 \%$ apresentam valores na faixa de 10 a $100 \mathrm{mg} / \mathrm{L} ; 63,4 \%$ entre 100 e $250 \mathrm{mg} / \mathrm{L}$; e $15,7 \%$ entre 250 e $500 \mathrm{mg} / \mathrm{L}$. A maioria, portanto, apresenta qualidade de boa a razoável conforme classificação utilizada por Menegasse et al. (2003). Uma pequena parcela apresenta elevados valores de STD, dos quais $2,6 \%$ na faixa de 500 a 1.000 $\mathrm{mg} / \mathrm{L}$ e $1,3 \%$ com valores maiores que $1.000 \mathrm{mg} / \mathrm{L}$ sendo já consideradas águas salobras (Tab. 4).

Os valores anômalos de STD (maiores que 500 $\mathrm{mg} / \mathrm{L}$ ) ocorrem, em sua maioria, em poços situados em Salto (SP), próximos às áreas de descarga dos aquíferos em drenagens, e um deles na proximidade de um aterro em Indaiatuba. Ezaki (2011) associou as elevadas concentrações de $\mathrm{HCO}_{3}{ }^{-}, \mathrm{SO}_{4}{ }^{2-}$ e $\mathrm{Cl}^{-}$nas águas às porções confinadas ou de circulação isolada/restrita nos sistemas aquíferos. Os elevados teores de STD também implicam em elevada dureza e consequente desativação de alguns poços em indústrias, em função de problemas de incrustação em tubulações ou devido interferência nos processos de produção.

0 nitrato é utilizado como indicador da contaminação das águas subterrâneas, por apresentar alta mobilidade na água subterrânea e persistência, podendo atingir extensas áreas (Companhia de Tecnologia de Saneamento Ambiental de São Paulo, 2007). Nas áreas urbanas, onde os sistemas de saneamento são precários, a presença de nitrato nas águas também pode estar associada a contaminantes microbiológicos (bactérias patogênicas, vírus e protozoários) e, em alguns casos, substâncias orgânicas sintéticas.

As principais fontes de nitrato para as águas podem estar associadas ao uso excessivo de fertilizantes inorgânicos nitrogenados e de esterco nas atividades agrícolas, ao vazamento de redes coletoras de efluentes e de tanques e fossas sépticas (excreta humano e animal), à falta de saneamento nas zonas urbanas, entre outras. No solo, estes fertilizantes inorgânicos e os resíduos contendo nitrogênio orgânico são decompostos formando amônia, que é oxidado a nitrito e nitrato. Parte do nitrato pode ser absorvida pelas plantas, mas o excedente move-se rapidamente para as águas subterrâneas.

0 limite de ingestão de nitrato pela água é de 10 $\mathrm{mg} / \mathrm{L}$ de $\mathrm{N}^{-\mathrm{NO}_{3}}{ }^{-}$(ou o equivalente a $45 \mathrm{mg} / \mathrm{L} \mathrm{NO}_{3}{ }^{-}$), conforme o Ministério da Saúde. Sua toxicidade é principalmente atribuída à redução do nitrato a nitrito no organismo, cujo efeito biológico é a oxidação de hemoglobinas normais a metahemoglobinas (10\% ou mais) que são instáveis para o transporte de oxigênio para os tecidos (World Health Organization, 2007). A Companhia de Tecnologia de Saneamento Ambiental de São 
Paulo (2007) considera concentrações de nitrogênio nitrato acima de 5,0 mg/L como indicativas de alteração do equilíbrio natural, e adota esta concentração como um valor de prevenção.

$\mathrm{Na}$ área estudada foram constatados apenas 3 casos que ultrapassam o limite de potabilidade, em condomínio de Indaiatuba (poços IG $\mathrm{n}^{\text {os }} 4247,4277$ e 4293) (Fig. 7). Em outros 4 poços (poços IG n ${ }^{\text {os }} 1765$,

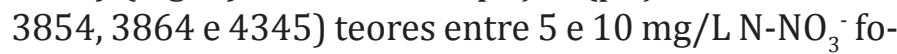
ram constatados, já indicando a influência de atividade antrópica sobre a qualidade das águas. Estes poços estão situados nas porções mais antigas das cidades onde normalmente o uso de fossas foi mais intenso e onde a concentração de edificações ocorre de forma mais adensada, aumentando a carga potencial de contaminação.

\section{Conclusões}

A caracterização hidroquímica das águas subterrâneas na região estudada indica predomínio de águas bicarbonatadas cálcicas e sódicas no Aquífero Cristalino com pH médio de 7,35 e condutividade elétrica média de $170 \mu \mathrm{S} / \mathrm{cm}$, e de águas bicarbonatadas sódicas no Aquífero Tubarão e, secundariamente, sulfatadas sódicas, com pH médio de 8,15 e condutividade elétrica um pouco mais elevada de $273 \mu \mathrm{S} / \mathrm{cm}$. As águas de alguns poços que explotam o Cristalino, indicam que há influência das propriedades mineralógicas da cobertura sedimentar sobre sua composição, como nos poços no 16,19 e 35 , que apresentam maior condutividade elétrica. As águas dos poços mistos assemelham-se às do Aquífero Tubarão.

As águas destes aquíferos são, em geral, fracamente mineralizadas $(<300 \mu \mathrm{S} / \mathrm{cm})$, mas há uma tendência da salinidade (expressa em termos de condutividade elétrica) aumentar das áreas de recarga para as de descarga nos principais rios da região (Tietê, Jundiaí, Buru, Capivari). Valores anômalos (> $500 \mathrm{mg} / \mathrm{L}$ ) e águas salobras ocorrem em Salto (SP) e podem estar associados a circulação restrita e local de águas do Aquífero Tubarão.

Isótopos de D (-52\%0) e ${ }^{18} \mathrm{O}(<-9 \%$ ) também indicam que porções do aquífero podem estar (semi-) confinadas com a presença de águas de recarga mais antigas e associadas a um período em que o clima era frio. Um aprofundamento dos estudos com o objetivo de avaliar a recarga do Aquífero Tubarão pode confirmar, portanto, a necessidade de controle na extração das águas por captações em poços.

A avaliação da qualidade das águas a partir dos parâmetros analisados indica, de modo geral, que as águas dos poços amostrados apresentam boa qualidade. A ocorrência de casos de contaminação por nitrato é ainda pontual, já sofrendo influência de cargas potenciais de contaminação associadas à ocupação urbana, embora mereçam um acompanhamento da evolução das concentrações e de ocorrência de novos casos. Os elevados valores de ferro e de manganês encontrados, respectivamente, em $9,75 \%$ e $15,60 \%$ dos poços, podem estar relacionados às características das formações geológicas da região ou a problemas construtivos do poço, mas a investigação da origem destes metais deve ser aprofundada em estudos complementares. As anomalias de fluoreto ocorrem, principalmente, em poços particulares de Salto e Indaiatuba, e estão associadas à alteração de rochas sedimentares (no Aquífero Tubarão) e de granitos (no Aquífero Cristalino).

Agradecimentos - Os autores agradecem ao FEHIDRO pelo auxílio financeiro concedido (Contrato FEHIDRO 450/2006), a Francisco Antonio Moschini (SAE Salto) e Felipe Rodrigues Ferroni (LEBAC-UNESP) pela colaboração nos trabalhos de amostragem, a Ramon Aravena (Universidade de Waterloo) pelas indicações bibliográficas, e a Renan Penasso Pacheco pela confecção de algumas figuras.

\section{Referências}

Almeida, F.F.M., Hasui,Y., Ponçano, W.L., Dantas, A.S.L., Carneiro, C.D., Melo, M.S. \& Bistrichi, C.A. 1981. Mapa Geológico do Estado de São Paulo. Nota Explicativa. São Paulo, IPT, v. 1, Escala 1:500.000.

American Public Health Association / American Water Works Association / Water Environment Federation. 1995. Standard methods for the Examination of Water and Wastewater. 19. Ed. Washington, American Public Health Association,

Aravena, R., Wassenaar, L. \& Plumer, L.N. 1995. Carbon 14 Groundwater ages with Methanogenesis. Water Resources Research, 31(9): 2307-2317.

Bistrichi, C.A., Carneiro, C.D.R., Dantas, A.S.L., Ponçano, W.L., Campanha, G.C., Nagata, N., Almeida, M.A., Stein, D.P., Melo, M.S. \& Cremonini, O.D. 1981. Mapa Geológico do Estado de São Paulo. São Paulo, IPT, v. 2, Escala 1:500.000.

Brasil. Ministério da Saúde. 2011. Portaria no 2914 de 12 de dezembro de 2011. Dispõe sobre os procedimentos de controle e de vigilância da qualidade da água para consumo humano e seu padrão de potabilidade. Diário Oficial da União, Brasília, 14 dez. 2011, Seção 1, p. 39.

Campos, H.C.N.S. 1993. Caracterização e cartografia das províncias hidrogeoquímicas do Estado de São Paulo. São Paulo, 177p. Tese de Doutorado. Instituto de Geociências, Universidade de São Paulo.

Canadian Council of Resource and Environment Ministers. 1987. Canadian water quality guidelines. Prepared by the Task Force on Water Quality Guidelines.

Companhia de Saneamento Básico do Estado de São Paulo. SABESP. 2013. Flúor na água contribui para prevenção e controle de cárie dentária. Notícias. 03/10/2013. Disponível em: www.sabesp.com.br. Acesso em: 10/10/2013.

Companhia de Saneamento de Minas Gerais/ Hidrosistemas Engenharia de Recursos Hídricos Ltda. 1995. Disponibilidades hídricas subterrâneas no Estado de Minas Gerais. Belo Horizonte, Ed. Sergio Menin Teixeira de Souza, 525 p. Companhia de Tecnologia de Saneamento Ambiental de São Paulo. CETESB. 2007. Relatório de Qualidade das Águas Subterrâneas do Estado de São Paulo 2004-2006. São Paulo, CETESB. Disponível em: www.cetesb.sp.gov.br. Acesso em: 15/12/2012. 
Custodio, E. \& Llamas, M.R. 1983. Hidrologia Subterranea. 2 ed. Barcelona, Omega, $2 \mathrm{v}$.

Departamento de Águas e Energia Elétrica / Universidade Estadual Paulista-UNESP. 1980. Mapeamento faciológico do Subgrupo Tubarão. Convênio DAEE-UNESP, Escala 1:50.000.

Departamento de Águas e Energia Elétrica. 1981a. Estudo de Águas Subterrâneas. Região Administrativa 5. Campinas. São Paulo, DAEE, 2 v.

Departamento de Águas e Energia Elétrica. 1981b. Estudo de Águas Subterrâneas. Região Administrativa 4. Sorocaba. São Paulo, DAEE, 2 v.

Diogo, A., Bertachini, A.C., Campos, H.C.N.S. \& Silva, R.B.G. 1981. Estudo preliminar das características hidráulicas e hidroquímicas do Grupo Tubarão no Estado de São Paulo. In: SIMPÓSIO REGIONAL DE GEOLOGIA, 3, Curitiba. Atas..., Curitiba, SBG., v. 1, p. 359-368.

Diniz, H.N. 1990. Estudo hidrogeológico do. Subgrupo ltararé no médio rio Tietê. Município de. Tietê, SP. São Paulo, 118p. Dissertação de Mestrado. Instituto de Geociências, Universidade de São Paulo.

Ezaki, S. 2011. Hidrogeoquímica dos Aquíferos Tubarão e Cristalino na Região de Salto (SP). São Paulo, 180 p. Tese de Doutorado. Instituto de Geociências, Universidade de São Paulo.

Galembeck, T.M.B. 1997. o Complexo Múltiplo, Centro e Plurisserial Itu-SP. Rio Claro, 374 p. Tese de Doutorado. Instituto de Geociências e Ciências Exatas, Universidade Estadual Paulista Júlio de Mesquita Filho.

Hirata, R., Gesicki, A., Sracek, O., Betolo, R., Giannini, P.C. \& Aravena, R. 2011. Relation between sedimentary framework and hydrogeology in the Guarani Aquifer System in São Paulo State, Brazil. Journal of South American Earth Sciences, 31: 444-456.

Hypolito, R., Ezaki, S. \& Pérez-Aguilar, A. 2010. Fluoreto nas águas subterrâneas dos aquíferos Tubarão e Cristalino, região de Salto-Indaiatuba (SP). REM: Revista Escola de Minas, 63(4): 715-726.

Hypolito, R., Andrade, S., Ezaki, S., Marques, J.F. \& Nascimento, S.C. 2009. Método para Amostragem e Detecção de Íons em Águas da Zona Não Saturada. Analytica, 38: 8592.

Instituto Geológico. 1990. Subsídios do meio físico-geológico ao planejamento da região do Município de Sorocaba (SP). São Paulo, IG/SMA. 1v. e mapas (Relatório Técnico do Instituto Geológico).

Instituto Geológico. 1991. Subsídios do meio físico-geológico ao planejamento do Município de Itu (SP). São Paulo, IG/ SMA, 2 v. (Relatório Técnico do Instituto Geológico).

Instituto Geológico. 1993. Subsídios do meio físico-geológico ao planejamento do Município de Campinas (SP). Programa Cartas Geológicas e Geotécnicas para o Planejamento Ambiental na Região de Sorocaba e Campinas. São Paulo, IG/SMA, 3v. (Relatório Técnico do Instituto Geológico).

Instituto Geológico. 1995. Subsídios para o planejamento regional e urbano do meio físico na porção média da bacia do Rio Piracicaba. São Paulo, IG/SMA. (Relatório Técnico do Instituto Geológico).

Instituto Geológico. 2012. Identificação de Áreas Potenciais de Restrição e Controle de Captação e Uso das Águas Subterrâneas na Porção Sul da UGRHI 05 - Projeto ARC-TUB1. São Paulo, IG/SMA, 2v. (Relatório Técnico do Instituto Geológico).

Menegasse, L.N., Oliveira, F.R., Mourão, M.A.A., Duarte, U.,
Castro, R.E., Diniz, A.M.A., Elmiro, M.A.Y. \& Pereira. P. E. 2003. Hidroquímica das Águas Subterrâneas do Médio Jequitinhonha, Minas Gerais, Brasil. Revista Latino-Americana de Hidrogeologia, 3: 49-58.

Neves, M.A. 2005. Análise integrada aplicada à exploração de água subterrânea na Bacia do Rio Jundiaí (SP). Rio Claro, 200 p. Tese de Doutorado. Instituto de Geociências e Ciências Exatas, Universidade Estadual Paulista Júlio de Mesquita Filho.

Pereira, S.Y. 1997. Proposta de representação cartográfica na avaliação para estudo de planejamento e meio ambiente. Exemplo da Região Metropolitana de Campinas-SP. São Paulo, 190 p. Tese de Doutorado. Instituto de Geociências, Universidade de São Paulo.

Petri, S. \& Pires, F.A. 1992. O Subgrupo Itararé (Permocarbonífero) na região do Médio Tietê, Estado de São Paulo. Revista Brasileira de Geociências, 22(3): 301-310.

Sachs, L.L.B. 1999a. Programa Levantamentos Geológicos Básicos do Brasil: Integração Geológica da Folha São Paulo. SF-23-Y-C. Estado de São Paulo. Mapa Geológico. São Paulo, CPRM, Escala 1:250.000,

Sachs, L.L.B. 1999b. Programa Levantamentos Geológicos Básicos do Brasil: Integração Geológica da Folha São Paulo. SF-23-Y-C. Estado de São Paulo. Nota Explicativa. São Paulo, CPRM, 36 p., il., mapas, escala 1:250.000.

Salvetti, R.A.P. 2005. Sistemas Deposicionais e Paleogeografia do Subgrupo Itararé (Neopaleozóico da Bacia do Paraná), na Região entre Itu e Indaiatuba, SP. São Paulo, 100 p. Dissertação de Mestrado. Instituto de Geociências, Universidade de São Paulo.

Santos, P.R. 1996. Condicionamento geológico da sedimentação glacial: o Neopaleozóico da Bacia do Paraná e o Terciário da Antártida. São Paulo, 111p. Tese de Livre Docência. Instituto de Geociências, Universidade de São Paulo.

Sistema Nacional de Informações sobre Saneamento / Ministério das Cidades. 2008. Diagnóstico dos Serviços de Água e Esgoto. Disponível em: http://www.snis.gov.br. Acesso em: 10/10/2012.

Stevaux, J.C., Souza Filho, E.E., Teixeira, J.A. \& Landim, P.M.B. 1987. Sistemas deposicionais do Subgrupo Itararé (P-CP na bacia hidrográfica do baixo Rio Capivari (SP): um modelo de prospecção de água subterrânea. In: SIMP. REG. GEOL., 6, Rio Claro, 1987. Atas... Rio Claro, SBG, v.1, p.335374.

Vidal, A.C. 2002. Estudo hidrogeológico do Aqüífero Tubarão na área de afloramento da porção central do Estado de São Paulo. Rio Claro, 109p. Tese de Doutorado. Instituto de Geociências e Ciências Exatas, UNESP,

Vidal, A.C., Rostirolla, S.P. \& Kiang, C.H. 2005. Análise de favorabilidade para a exploração de água subterrânea na Região do Médio Tietê, Estado de São Paulo. Revista Brasileira de Geociências, 35: 475-481.

World Health Organization. 2003. Iron in drinking-water. $\mathrm{Ba}$ ckground document for preparation of WHO Guidelines for Drinking-water Quality. Geneva, WHO Press. (WHO/SDE/ WSH/03.04/8).

World Health Organization. 2006. Fluoride in Drinking-water. World Health Organization titles with IWA Publishing. Printed by TJ International (Ltd), Padstow, Cornwall - UK.

World Health Organization. 2007. Nitrate and nitrite in drinking-water. Background document for development of WHO Guidelines for Drinking-water Quality. Geneva, WHO Press. (WHO/SDE/WSH/07.01/16).

Zalán, P.V., Wolf, S., Conceição, J.C.J., Astolfi, M.A.M., Vieira, I.S., 
Appi, V.T., Zanotto, O.A. \& Marques, A. 1991. Tectonics and sedimentation of the Paraná Basin. In: Ulbrich, H. \& Ro- cha Campos, A.C. (Ed). Gondwana Seven. Proceedings. São Paulo, p. 83-117.

Manuscrito 518.

Editores: Carla E. Barros 
